\title{
DEATHS FROM FALLS AND FRACTURES
}

\section{COMPARISON OF MORTALITY IN SCOTLAND AND THE UNITED STATES WITH THAT IN ENGLAND AND WALES}

\author{
T. P. EDDY
}

Department of Human Nutrition, London School of Hygiene and Tropical Medicine, Keppel Street, London WCIE 7HT

Eddy (1972) demonstrated a close relationship between mortality in England and Wales attributed to fractures of the long bones in the elderly and mortality from domestic falls. The mortalities appeared to be related to the epidemiology of osteoporosis and other causes of bone fragility in the elderly and to morbidity from fractures. Available published statistics of mortality from domestic falls over the age of 55 years were used to show secular trends of mortality from fractures of long bones, for which national statistics were not available before 1950 . A study covering the twentieth

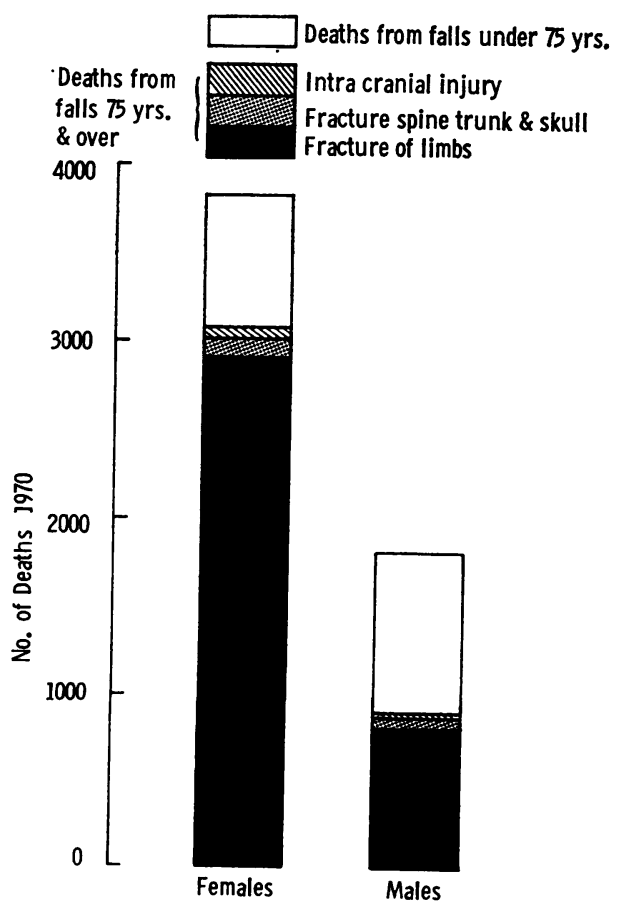

Fig. 1. The nature of injury in male and female deaths from falls at age 75 years and over (from Table 18d, General Register Office, 1970). century showed that, although the total mortalities from domestic falls of 10-year age groups of men and women over 55 years of age were substantially different, the trends were similar and there were close relationships between these age groups in the two sexes.

It was proposed that the trends in mortality could be explained by a combination of historical factors, which had governed skeletal growth from childhood to the third decade of life, with contemporary factors which affected skeletal homeostasis later in life.

The published national mortality statistics for Scotland (Registrar General for Scotland, annually) and the United States of America (United States Government, annually) do not give details of domestic falls comparable with those (General Register Office, annually) used by Eddy (1972) for England and Wales, nor are there details of the 'nature of injury' ('N' classification) to show the age and sex incidence of deaths from fractures. But it appears that the total deaths attributable to falls since $1950^{*}$ at ages 75 and over are nearly as closely related to mortality from fractures as are domestic falls. This is illustrated in Fig. 1, which shows that the vast majority of deaths from falls in England and Wales occurring at ages 75 years and over are due to fractures of the limbs. The coefficients of correlation between yearly death rates in England and Wales between 1950 and 1970 (General Register Office, annually) for fractures of the femur (N820-1) and for all falls (E900-4, 7th revision) at ages 75-84 years were $r=0.90$ for men and $r=0.84$ for women; at age $85+$ they were $r=0.84$ for men and $r=0.85$ for women. As my previous paper showed a close relationship between annual mortalities of 10-year age groups above 55 years, mortality over age 75 years may be accepted as a fair indicator of more general trends in elderly people. In the United States, Iskrant (1968) found the same relationships between mortalities from falls and

*Accidental falls : E880-7 in 8th revision of the International Classification of Diseases; $\mathrm{E900-4}$ in previous editions of ICD. 
fractures in the elderly and concluded that deaths from falls appear to be positively associated with bone fragility. Mortality of elderly women, and to a lesser extent of elderly men, from falls in urban areas was lower in areas with naturally fluoridated water than in non-fluoridated areas.

\section{RESULTS}

Figures $2 \mathrm{a}$ and $2 \mathrm{~b}$ show standardized mortality rates per cent based on direct standardization of mortality rates of age groups $75-, 85+$, similar to those given by Eddy (1972), in which annual mortalities for Scotland and the USA are compared 3 with mortalities for England and Wales. The@ comparisons are based on 200 expected combined male and female deaths in England and Wales in the total male and female population at age in the census? year 1961 taken as standard.

The American mortalities are subdivided into $\frac{\bar{\sigma}}{\vec{\phi}}$ mortalities of American 'whites' and 'non-whites'. The vast majority, both of the population and of deaths of 'non-whites' are American Negroes and in $\vec{\circ}$ effect the comparison is between 'whites' and $\rightarrow$ Negroes.

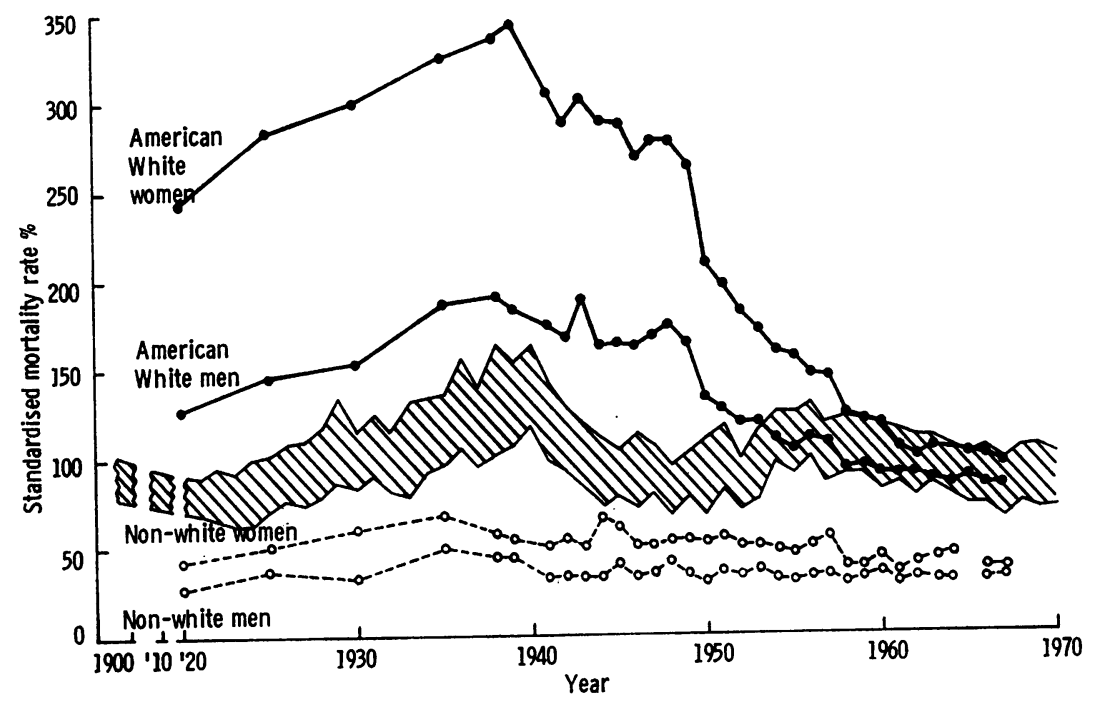

Fio. 2(a). Comparison of annual standardized mortalities from falls of American men and women aged $75+$ years. The shaded area is enclosed by the lines joining standardized mortalities for men and women in England and Wales. Comparisons are based on 200 expected male and femalo deaths in the population of England and Wales in the standard census year 1961 .

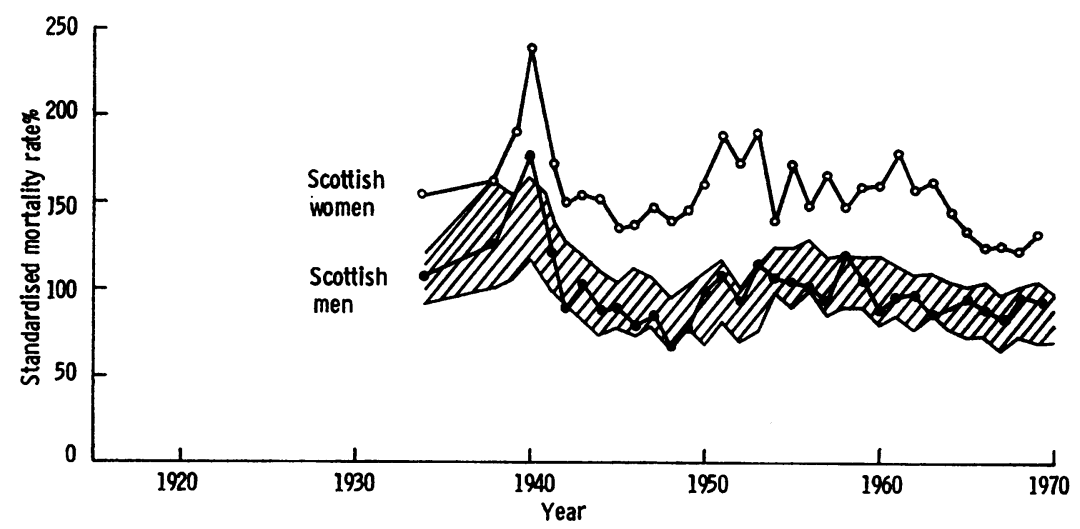

FiG. 2(b). Standardized annual mortalities for Scotland, as in Fig. 2(a), compared with England and Wales. 


\section{Mortality In ENGland, Wales and Scotland}

The secular trend of mortalities in England and Wales is similar to that for domestic falls occurring over 55 years of age described previously by Eddy (1972). Mortality rose to a peak in 1940 (the very high peak for Scotland may be attributable to the inception of the air raid precautions blackout) followed by a recession over the decade of wartime rationing and austerity which, it was suggested, may have been due to greater activity of elderly people in wartime. This was followed by a rise in the succeeding six years followed by a decline since 1960 . The Scottish mortalities show a similar trend. The mortality of Scottish women, however, has been consistently higher than that of women in England and Wales, while that of Scottish men, though it was generally rather higher, approximated to or in some years was identical with that of men in England and Wales.

\section{MORTALITY IN THE UNITED STATES OF AMERICA}

There is a striking difference between mortalities of American 'non-whites', which are consistently low and show little variation, and those of American 'whites', which show a steady decline from a very

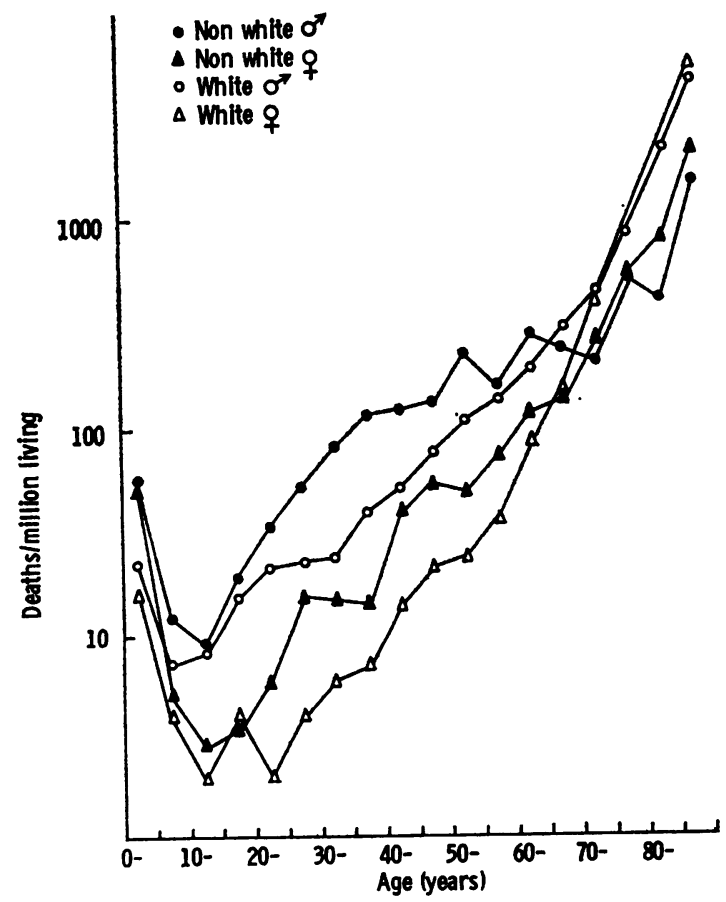

Fig. 3. Deaths from all falls (E900-4) per million living, by age and sex: USA 1960 (US Government 1960, Tables 5-9). high level earlier in the century to a mortality equivalent to that in England and Wales since 1958, and is now, particularly for women, below the Scottish mortality.

The consistently low mortality of 'non-whites' is remarkable, for mortality from all other forms of violence is much higher in 'non-whites' than in 'whites', and is so for falls below the age of 65 years, as shown in Figure 3. Iskrant (1968) gives a similar figure for falls over the age of 45 years by age, colour, and sex for the United States in 1959-61. It is also remarkable that even at these lower mortalities the contradiction of female preponderance of mortality from falls in old age is maintained, for generally the mortality of males from violence substantially exceeds that of females. $A$ fortiori this excess of male mortality would be expected to apply to 'non-whites'. Total male mortality from all causes is, of course, universally higher than female mortality.

\section{Discussion}

\section{Height and Skeletal Mass}

ENGland, Wales, AND Scotland Eddy (1972) showed that mortality from fracture of the femur in England and Wales increased in a progression from south to north in three defined areas-south, midlands, and north-that differences in mortality were significantly related to observed differences in height and, as it was proposed, in skeletal mass as a function of height (Table I). Though measurements of adult height made in the nineteenth century suggested that the Scots were taller than the English, the height of conscripted national servicemen analysed by Martin (1949) showed that the progressive decline in height from south to north continued into Scotland, for the mean height of

\section{TABLE I}

MEAN ANNUAL STANDARDIZED DEATH RATES 1966-69 MEAN MILLION POPULATION AT AGE 55 YEARS AND OVER FOR FRACTURE OF FEMUR (N220-1) AND STATURES OF SCHOOLCHILDREN IN 1908-11 (EDDY, 1972 CORRECTED)

\begin{tabular}{|c|c|c|c|c|c|c|}
\hline \multirow[b]{3}{*}{ Region } & \multicolumn{3}{|c|}{ Males } & \multicolumn{3}{|c|}{ Females } \\
\hline & \multirow{2}{*}{$\begin{array}{l}\text { Death } \\
\text { Rate }\end{array}$} & \multicolumn{2}{|c|}{$\begin{array}{c}\text { Height Indices } \\
\text { Percentile }\end{array}$} & \multirow{2}{*}{$\begin{array}{l}\text { Death } \\
\text { Rate }\end{array}$} & \multicolumn{2}{|c|}{$\begin{array}{c}\text { Height Indices } \\
\text { Percentile }\end{array}$} \\
\hline & & $>75$ th & $<25$ th & & $>75$ th & $<25$ th \\
\hline $\begin{array}{c}\text { South } \\
\text { Urban } \\
\text { Rural } \\
\text { Midlands }\end{array}$ & $\begin{array}{l}124 \cdot 4 \\
116 \cdot 3\end{array}$ & 45 & $5 \cdot 5$ & $\begin{array}{l}358 \cdot 0 \\
384 \cdot 9\end{array}$ & 46 & $5 \cdot 6$ \\
\hline $\begin{array}{l}\text { Urban } \\
\text { Rural } \\
\text { North }\end{array}$ & $\begin{array}{l}185 \cdot 7 \\
178 \cdot 1\end{array}$ & 26 & 21 & $\begin{array}{l}486 \cdot 6 \\
476 \cdot 3\end{array}$ & 26 & 29 \\
\hline $\begin{array}{l}\text { Urban } \\
\text { Rural }\end{array}$ & $\begin{array}{l}227 \cdot 8 \\
216 \cdot 4\end{array}$ & $2 \cdot 4$ & 46 & $\begin{array}{l}542 \cdot 4 \\
590 \cdot 2\end{array}$ & $2 \cdot 5$ & 56 \\
\hline
\end{tabular}


Scottish men was $1.3 \mathrm{~cm}(0.5 \mathrm{in})$ shorter than that of the English. Martin also confirmed earlier observations that adults from rural areas were taller than urban adults.

In a representative sample of mothers examined in 1958 for the British Perinatal Survey, Baird and Thomson (1969) showed that in three defined areassouth, central,.and north (which included Scotland) - there was a decreasing proportion of tall women together with an increasing proportion of short women, progressing from south to north. In each of the three areas, women in rural districts were taller than women in urban districts. A separate sample of women from Aberdeen, in the north of Scotland, were of lower stature than any of the other groups described in the survey.

The negative relationship of mean stature with latitude and mortality could be one explanation of the higher mortality from falls (and, by inference, from fractures of limbs) in elderly people in Scotland.

In the regional mortalities from fracture of the femur in 1966-69 (Table I) the mortality of males in rural areas was lower than in urban areas, as would be expected if they had greater stature, but this did not apply to women. The residence of old people at death is less likely than formerly to indicate their childhood origin in town or country. There have been increasingly rapid social changes in the population in the 25 years since the second world war, the number of people employed in agriculture has been greatly reduced, and an increasing number of old people live in institutions for the care of the elderly. At death the institution is certified as the residence of the deceased and this may fail to reveal an urban or rural origin.

In 1950 (Registrar General Table 18A) the place of occurrence of the accident in $60 \%$ of men and $73 \%$ of women aged over 65 years who died from falls was reported to be in their homes; in 1958-60 $62 \%$ of men and $67 \%$ of women fell at home, but in $1968-70$ these proportions were reduced to $52 \%$ of men and $53 \%$ of women. Over the same period of 20 years the number of elderly people aged over 65 years reported to have died from falls in residential institutions rose from $11 \%$ (men) and $10 \%$ (women) in 1950 to $16 \%$ and $19 \%$ in $1958-60$ and to $19 \%$ and $21 \%$ in 1968-70. Table II shows that urban and rural mortalities from accidents in elderly men and women in 1968-70 were similar to those given in Table I for fractures of the femur-only men show a lower mortality in rural districts; but earlier in 1958-60 and 1928-30 it is shown in Table II that the difference between town and country was increasingly marked and applied to both men and women. The lower mortality experienced by elderly people from
TABLE II

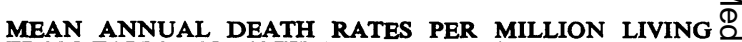
FROM FALLS AND 'OTHER ACCIDENTS' OVER 75 YEARS

\begin{tabular}{|c|c|c|c|c|c|}
\hline \multirow[b]{2}{*}{ Date } & \multirow[b]{2}{*}{ Cause } & \multicolumn{2}{|c|}{ Men } & \multicolumn{2}{|c|}{ Women } \\
\hline & & Urban & Rural & Urban & Rural \\
\hline $1968-70$ & BE48 & 1,670 & 1,456 & 2,377 & 2,482 \\
\hline $1958-60$ & BE 48 & 2,182 & 1,827 & 2,740 & 2,626 \\
\hline $1928-30$ & Falls & 1,823 & 841 & 2,400 & 1,521 \\
\hline
\end{tabular}

Statistics for falls in rural and urban areas were not published in $\overrightarrow{\vec{H}}$ 1968-70 and 1958-60. Cause of death BE 48 in Table 19 of Registrar $\vec{\omega}$ General's Annual Reviews for these years is for all accidents excluding motor accidents. At ages $75+$, comparison with Registrar General's $(1)$ Table 18 shows that $79 \%$ of male deaths and $85 \%$ of female deaths attributed to BE 48 were from falls (E900-4, 7th revision) in 1968-70. $J$ In $1958-60,73 \%$ of male and $82 \%$ of female deaths were from falls.

rural districts supports the view that deaths from falls and fractures are inversely related to skeletal 0 mass as measured by height.

United States of America Non-whites Bollet, Fngh, and Parson (1965), Gyepes, Mellins, and Katz (1962), and Nordin (1966) have all noticed that $\stackrel{\oplus}{\frac{}{\circ}}$ morbidity from osteoporosis and fracture of tie $\vec{\omega}$ proximal femur is much lower in American Negroes. than in 'whites'. Their low morbidity from thes causes is now well established and is attributed by Garn (1970) and Trotter and Peterson (1962) to a greater skeletal mass than that of Caucasians, which may be genetically determined. The same appears to $\bigcirc$ be true of Bantu and other African people south of $\varrho$ the Sahara. There is evidence that both sexes of the $\vec{B}$ American Negroes, despite their socio-economic 3 disadvantages, are taller and heavier than their Caucasian counterparts.

The greater skeletal mass of peoples of African $\bar{\triangle}$ origin, and consequently their lower susceptibility to $\stackrel{\odot}{?}$ fractures resulting from skeletal rarefaction, could $\frac{5}{3}$ account for the low mortality from falls (if these mortalities are indeed associated with fractures) that $\stackrel{\bigcirc}{\rho}$ is shown in Figure 2a. It is difficult to find any other explanation; faults in death certification or registra-음 tion would have to be enormous to account for the $>$ discrepancy between 'whites' and 'non-whites', and faults would be unlikely to produce records of such $N$ remarkable consistency.

American whites Hathaway and Foard (1960) gave practically all the available reliable data on the heights and weights of adults in the United States.o Nearly all their statistics, with the possible exception $\mathbb{\varnothing}$ of data given by the United States Department of $\stackrel{\oplus}{+}$ Agriculture in connection with household food $\square$ consumption surveys, refer to highly selected $\stackrel{\vec{\Phi}}{\mathbb{Q}}$ 
populations of college students, insured lives, and the United States army. The well-known data of the Association of Life Insurance Medical Directors and Actuarial Society of America (1912) collected from 1885 to 1908 , and earlier measurements of college students dating from 1857, are mostly from people of 'American' parentage and British ancestry who lived in States along the eastern seaboard. Men in these studies showed little decline of height with age but women in the medico-actuarial investigation showed a decline of $2.5 \mathrm{~cm}(1 \mathrm{in})$ between the ages of 25 and 60 years. In 1948-50, college men were $2.5 \mathrm{~cm}$ and college women $1.8 \mathrm{~cm}$ taller than collegers in 1928-30. Men and women were about $5 \mathrm{~cm}$ (2 in) taller in 1955 than in 1900. These data are similar to those for Britain and do not fully explain the rise in mortality from falls of American whites to a maximum in 1940 followed by a drop from that very high level; but they do not appear to include many measurements from lower socioeconomic classes or from immigrants.

Hathaway and Foard (1960) give details of the changes in the United States population between 1790 and 1950 resulting from changing patterns of immigration. There was an increasing pace of immigration between 1850 and 1910 followed by a marked decrease as a result of legislation after 1920. Before 1850 immigrants were mostly from northwest Europe of the same stock as the indigenous white American population at that time. After the influx of Irish, following famine in Ireland, the greatest change was a marked increase of immigrants from Italy and Russia after 1880 'who were much shorter', Hathaway and Foard reported, and therefore "it is not surprising that the United States soldiers in World War I in 1917-19 averaged less than those in the Civil War in the 1860'.

Immigration reached its peak in the decade 190110 owing to the high demand for unskilled labour, the proportions of 'native whites' of foreign parentage and foreign-born 'whites' reaching peaks of 14 and $14.5 \%$ - totalling for both groups together with those of mixed parentage about one-third of the population in 1910, a proportion that has been decreasing ever since. At this time Boas (1911) showed that immigrant Bohemians, Hebrews, and Sicilians were shorter than native-born Americans. The height of immigrants depended upon their age on arrival in America; if they arrived before the age of 20 years they grew taller than their relatives in the home country. Men born in the United States were about $2.5 \mathrm{~cm}$ taller than their immigrant fathers.

The high proportion of Caucasian immigrants of short stature earlier in the century, and the increased stature of their American descendants, could account for the earlier rise to a peak of high mortality in 1940 and the later rapid decline. About $40 \%$ of the expected deaths of American non-whites, upon which the standardized mortalities in Fig. 2a are based, occurred at age 85 years or over, when the expectation of life shown by American life tables given by Grove and Hetzel (1968) is only 4-5 years. The majority of expected deaths would therefore have occurred around the age of 85 years. In Fig. 4, showing the relative proportions of 'native whites' to 'foreign-born whites' at age $85+$ years given by Grove and Hetzel, there is a decline in 'foreign-born whites' after 1940 corresponding to the fall in

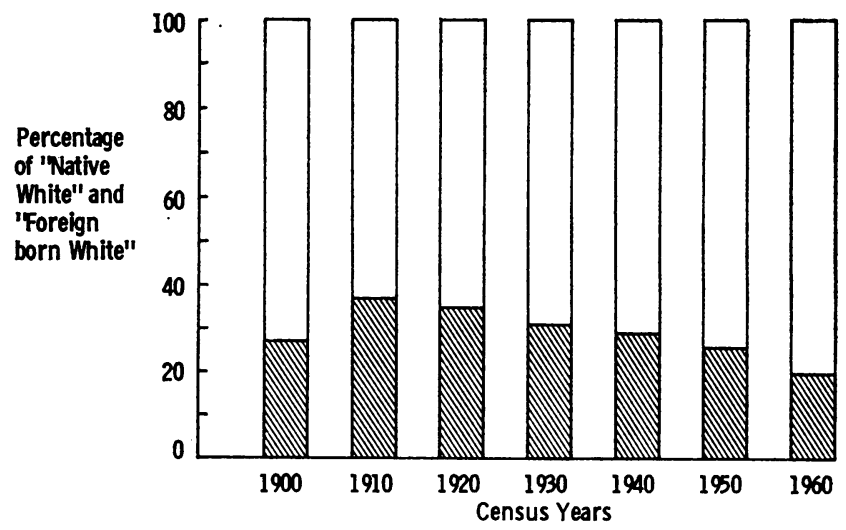

Fig. 4. Percentages of 'native whites' and 'foreign-born whites' at age $85+$ in successive census years, USA. 
mortality after 1940 . The removal by death of the foreign-born elderly immigrants, who may have been particularly susceptible to mortality from fractures and falls, following the virtual cessation of immigration after 1920 may be one of the principal factors in the drop in mortality after 1940. In Britain, Eddy (1972) suggested that the first steps towards the welfare state taken early in this century may have led to an increased mortality through the greater survival to old age of skeletal weaklings; in America the skeletal weaklings were imported.

\section{Vitamin D AND Fragility of Bone}

Nordin (1971), noting that frank osteomalacia is not uncommon among elderly people, found that calcium absorption in elderly men and women, particularly over the age of 70 years, is reduced, but that absorption rises with quite small doses of vitamin D. He therefore concluded that vitamin D deficiency is probably widespread among the elderly in Britain and that some scheme of fortification, similar to the fortification of baby foods which has practically abolished rickets, should be considered for old people. Exton-Smith, Hodkinson, and Stanton (1966) found a significant association of low bone density with a low calcium-phosphorus product, which was related to low intakes of vitamin D.

Changes in mortality in Britain cannot be related to changes in the dietary intake of vitamin $\mathbf{D}$ by old people. Though there is evidence of the occurrence of specific deficiency disease at present, there is no satisfactory evidence of any great change in dietary intake of vitamin $D$ by the elderly since the fortification of margarine became general in 1940 . But the relationship of mortality to latitude in Britain might mean that differences in the ultraviolet synthesis of vitamin $D$ in the skin might be one factor, just as it was a deciding factor in the geographical distribution of nutritional rickets when this was prevalent, as described by Hess (1930). The wartime recession in mortality was coincident with the extension of daylight saving to winter months from 1941 to 1944; 'double summer time' in the summer months extended daylight for an extra two hours in the evenings, and in subsequent years the customary period of five months was increased to 7-10 months. Combined with many factors affecting domestic life at the time, it is possible that the skins of elderly people were more exposed to daylight.

The difference in radiation from sunlight between the south of England and Scotland is considerable. Loomis (1967) pointed out that in London the sun is less than $35^{\circ}$ above the horizon for five months in the year but in Glasgow this period is increased to six months. Times given for hours per day of bright sunshine by Whitaker (1973) also show considerable differences between London $(4 \cdot 4)$, Glasgow (3.6), and Edinburgh (3.7). Loomis, using the data of Beckemeir (1958) that $1 \mathrm{~cm}^{2}$ of skin exposed to sunlight would synthesize up to $0.5 \mu \mathrm{g}$ (18 IU) of vitamin $\mathrm{D}$, calculated that the exposed cheeks of an infant would synthesize a dose of $10 \mu \mathrm{g}$ in three hours. The larger area of an adult face and exposed skin would presumably synthesize larger quantities and, approximately, a recommended dietary allowance of vitamin $\mathrm{D}$ of $10 \mu \mathrm{g}$ would be synthesized in one extra hour of exposure.

In the United States, fortification of milk with vitamin $D$ was begun early in the 1930s. The Food and Drugs Administration and the Council of Foods of the American Medical Association have approved fortification with $10 \mu \mathrm{g}$ vitamin D per litre (400 IU per quart) (United States Department of Agriculture, 1959). It has been estimated that about $85 \%$ of all milk sold in the United States is fortified (Guthrie, 1967). The fortification of milk with its high content of calcium and phosphorus is a particularly effectivo method of administering vitamin $D$. The reduction in mortality of American whites since 1940 coincides with this increase in dietary vitamin $\mathbf{D}$.

But when rickets was prevalent in the United States, Hess (1930) described the Negro, together with the immigrant communities in the States of the north-eastern seaboard, as the worst affected. There is, however, no evidence that the vitamin fortification of milk, or the lack of it, affected the mortality of non-whites. The correlation of mortality in Britain with height and of both with latitude, and of height with urban or rural residence within districts defined by latitude, all suggest a possible relationship with exposure to sunlight; but as regards height, the relationship, if it is causal, would have been operative in childhood not in old age, and it is possible that nutritional rickets in childhood may have been a factor leading to bone fragility in old age. If the mortality differences are in any degree attributable to present vitamin deficiency of the elderly, it would seem. judging from the British experience of recession of mortality in wartime, that a trial of vitamin fortification in Scotland would have an immediately measurable effect on mortality.

If this occurred it would give strong support to Nordin's recommendation. Perhaps the recent three-year experiment in winter daylight saving from 1969-71 may show an effect on mortality. 


\section{SUMMARY}

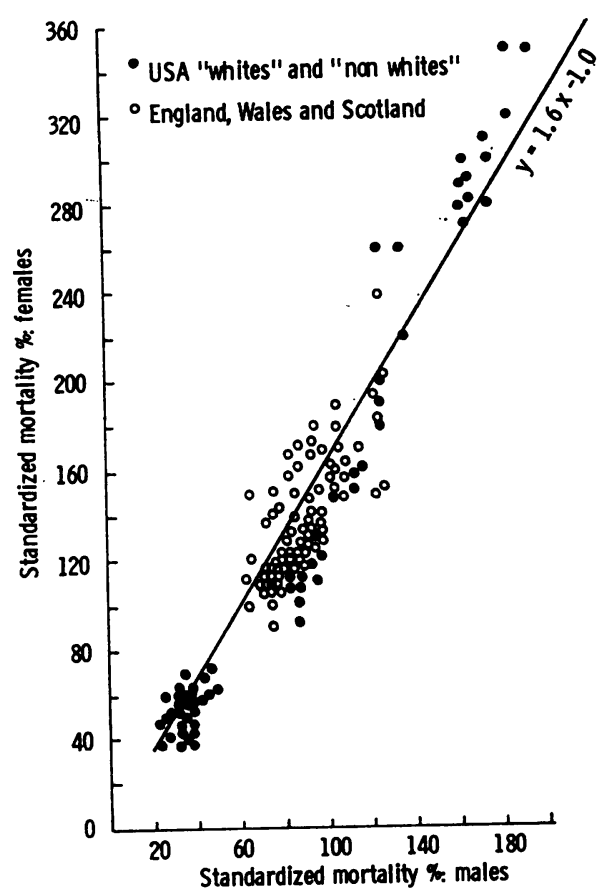

Fig. 5. Correlation between male and female standardized mortalities from falls over 75 years shown in Figure 2. American "nonwhites' form the distinct separate group of low mortalities at the origin of the regression line. For all mortalities, American and British, $\mathbf{r}=0.90$.

\section{Relationship of Male to Female Mortality}

It is evident from Figs. $2 a$ and $2 b$ that there is a close relationship between annual male and female mortalities in all the groups. The relationship is similar to that shown previously for domestic falls and fractures in England and Wales by Eddy (1972), and the duplication of annual peaks and troughs in male and female mortalities strongly supports the suggestion that some common and contemporary factors affected the mortality of each sex even though the total experiences of mortality were substantially different. Fig. 5 shows the relationship between male and female mortalities. Clearly, the American Negroes form a distinctly separate group from the American and British Caucasians; while they appear to be close to a point where male and female mortalities would be equal, the mortalities of the two sexes still maintain a similar relationship. Coefficients of linear correlation between male and female mortality for the different groups are:

$$
\begin{array}{ll}
\text { US whites and non-whites } & \mathrm{r}=0.93 \\
\text { England and Wales } & \mathrm{r}=0.91 \\
\text { Britain (including Scotland) } & \mathrm{r}=0.83 \\
\text { All groups } & \mathrm{r}=0.90
\end{array}
$$

In England and Wales there is a close relationship between total deaths attributed to falls and deaths attributed to fractures of limbs in men and women aged 75 years and over, similar to the relationship between deaths from domestic falls and fractures over the age of 55 years reported by Eddy (1972). This relationship enables comparisons to be made between published statistics of mortality from falls as indicators of comparative mortality from fractures in populations of elderly people in Britain (including Scotland) and the United States of America. Since 1931, annual Scottish mortalities have been higher but showed a similar trend to those in England and Wales with a recession during the wartime decade 1940-50 followed by a rise in 1950-60.

Throughout this century mortality from falls of elderly 'non-whites' in the USA has been much lower than Caucasian mortality in Britain, and the USA American 'whites' had a very high mortality early in this century rising to a peak in 1938, falling since then to reach the same level as in England and Wales by 1958 .

Possible causes for these differences between populations are: observed differences in secular trends in adult stature and hence in skeletal mass; the greater skeletal mass and lower susceptibility to osteoporosis and fracture of American Negroes; the effects of immigration on mean stature of the population of American 'whites'; the effect of increased dietary vitamin $D$ through fortification of American milk since 1930; the exposure of elderly people to sunlight and its relationship to latitude in Britain.

\section{REFERENCES}

Association of Life Insurance Medical Directors AND ACtuarial Society of AMERICA (1912). MedicoActuarial Mortality Investigations, $1,1$.

BaIRD, D. and Thomson, A. M. (1969). Chap. 2, p. 16General factors underlying perinatal mortality rates. Chap. 12, p. 211-The effects of obstetric and environmental factors on perinatal mortality by clinicopathological causes. In Perinatal Problems, 2nd Report of the 1958 British Perinatal Survey, edited by Neville R. Butler, and Eva D. Alberman. Livingstone, Edinburgh and London.

BeCKemeIER, H. (1958). Versuche zur maximalen antirachitischen UV-Aktivierung isolierter menschlicher Haut. Acta. biol. med. germ., 1, 756.

BoAs, F. (1911). Changes in bodily form of descendants of immigrants. U.S. Immigr. Comn. Rpts, 38, 127.

Bollet, A. J., Engh, G., and Parson, W. (1965). Epidemiology of osteoporosis, sex and race incidence of hip fractures. Arch. intern. Med., 116, 191. 
EDDY, T. P. (1972). Deaths from domestic falls and fractures. Brit. J. prev. soc. Med., 26, 173.

Exton-Smith, A. N., Hodkinson, H. M., and Stanton, B. R. (1966). Nutrition and metabolic bone disease in old age. Lancet, $2,999$.

GARN, S. M. (1970). The Earlier Gain and the Later Loss of Cortical Bone in Nutritional Perspective. Thomas, Springfield, Illinois.

General Register Office (annually). The Registrar General's Statistical Review of England and Wales for the year. HMSO, London.

Grove, R. D. and HeTzel, A. M. (1968). Vital Statistics Rates in the United States 1940-60. Population table 72 (pp. 789-791) and life tables 48-52 (pp. 306-313). National Center for Health Statistics, U.S. Department of Health, Education and Welfare, Washington, D.C.

GuTHRIE, H. A. (1967). In Introductory Nutrition, p. 202. Henry Kimpton, London.

Gyepes, M., Mellins, H. Z., and Katz, I. (1962). The low incidence of fracture of the hip in the Negro. J. Amer. med. Ass., 181, 1073.

HathaWAy, M. L. and Foard, E. D. (1960). Heights and Weights of Adults in the United States. Home Economics Research Report No. 10. Human Nutrition Research Division Agricultural Research Service, U.S. Department of Agriculture, Washington, D.C.

HEss, A. F. (1930). The geographical distribution of rickets. In Rickets: including Osteomalacia and Tetany, chap. 2, p. 38. Henry Kimpton, London.
IsKRANT, A. P. (1968). The etiology of fractured hips in females. Amer. J. publ. Hlth, 58, 485.

LoOMIs, W. F. (1967). Skin-pigment regulation of vitamin-D biosynthesis in man. Science, 157, 501.

MarTIN, W. J. (1949). The physique of young adult males. Mem. med. Res. Coun. (Lond.), No. 20. HMSO, London.

Nordin, B. E. C. (1966). International patterns of osteoporosis. Clin. Orthop. rel. Res., 45, 17. (1971). Clinical significance and pathogenesis of osteoporosis. Brit. med. J., 1, 571.

Registrar General for Scotland (annually). The Registrar General for Scotland Annual Report for the year. HMSO, Edinburgh.

Trotter, M. and Peterson, R. R. (1962). The relationship of ash weight and organic weight of human skeletons. J. Bone Jt Surg., 44A, 669.

United States Department of Agriculture (1959). Food: the Yearbook of Agriculture 1959, p. 21. U.S. Government Printing Office, Washington, D.C.

United States Government (annually). (i) Vital Statistics of the United States 1937-Mortality. U.S. Department of Health, Education and Welfare, Public Health Services. Deaths from selected causes by 5 -year age-groups, race and sex: United States. (ii) Mortality Statistics 1900-1936. U.S. Departmen of Commerce, Bureau of the Census. U.S. Govern ment Printing Office, Washington, D.C.

WHITAKER (1973). Whitaker's Almanack. Whitaker? London. 